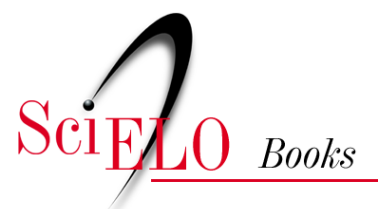

\title{
5 - Cuidado à saúde da criança indígena
}

\author{
Luiza Garnelo \\ Sully de Souza Sampaio \\ Ana Lúcia Pontes
}

GARNELO, L., SAMPAIO, S.S., and PONTES, A.L. Cuidado à saúde da criança indígena. In: Atenção diferenciada: a formação técnica de agentes indígenas de saúde do Alto Rio Negro [online]. Rio de Janeiro: Editora FIOCRUZ, 2019, pp. 89-118. Fazer saúde collection. ISBN: 978-65-5708-011-5. https://doi.org/10.7476/9786557080115.0006.

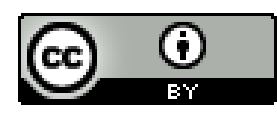

All the contents of this work, except where otherwise noted, is licensed under a Creative Commons Attribution 4.0 International license.

Todo o conteúdo deste trabalho, exceto quando houver ressalva, é publicado sob a licença Creative Commons Atribição 4.0. 


\section{5}

\section{Cuidado à saúde da criança indígena}

Neste capítulo apresentamos a experiência de implementação curricular do CTACIS no âmbito dos conteúdos e competências relativos ao que denominamos de cuidado à saúde da criança indígena. Pretendemos destacar estratégias didáticas utilizadas, definição de conteúdos e discutir os desafios do trabalho do AIS na atuação no cuidado à criança indígena.

O grupo populacional denominado criança não é uma categoria biológica natural nem consensual nos diversos contextos socioculturais e institucionais. O Fundo das Nações Unidas para a Infância (Unicef) o define como toda pessoa menor de 18 anos de idade; o Estatuto da Criança e Adolescente (ECA) limita-o à idade de 12 anos incompletos; já o MS considera como público-alvo das políticas de saúde da criança aquelas com até 10 anos de idade. No âmbito dos povos indígenas, o entendimento do que seja infância, ou categoria social similar, demanda a construção de um olhar específico e diferenciado. Na implementação de ações de saúde pelas equipes multidisciplinares de saúde indígena, optamos por tentar conciliar as diretrizes gerais e nacionais com as concepções e práticas locais voltadas para esse público.

Segundo o Censo 2010, na estrutura por idade da população indígena, o grupo etário de crianças e adolescente (entendido por esse órgão como as pessoas menores de 14 anos) representa 36,2\% do total. O maior peso relativo desse grupo etário se aprofunda na população indígena residente em área rural, passando a corresponder a $45 \%$ da população (IBGE, 20 I0). Se analisarmos as pirâmides populacionais produzidas pelo Instituto Brasileiro de Geografia e Estatística (IBCE), percebe-se que esse é um perfil típico da região Norte, onde se localiza o Alto Rio Negro. Naquela região observa-se que, para a população masculina, a faixa etária de 0 a 4 anos corresponde a 16,1\%, e a feminina a 16,6\%; na faixa etária de 5 a 9 anos, homens e mulheres correspondem a 14 , $7 \%$ e 15\%, respectivamente. Na faixa etária de 10 a 14 anos essa proporção é de 13\% 
para homens e 13, 1\% para as mulheres indígenas (Disponível em:<http://indigenas. ibge.gov.br/piramide-etaria-2.html>).

Embora relevantes, tais informações são incapazes de subsidiar o trabalho do agente de saúde nas aldeias. Em razão disso, o exercício de construção da pirâmide populacional da aldeia de cada estudante também foi desenvolvido no CTACIS. Dentre os resultados da iniciativa, identificou-se, de modo congruente com os achados do IBGE, que nas comunidades indígenas do Alto Rio Negro predominava o segmento menor que 15 anos, conforme a Figura 13.

Figura 13 - Pirâmide populacional de comunidade

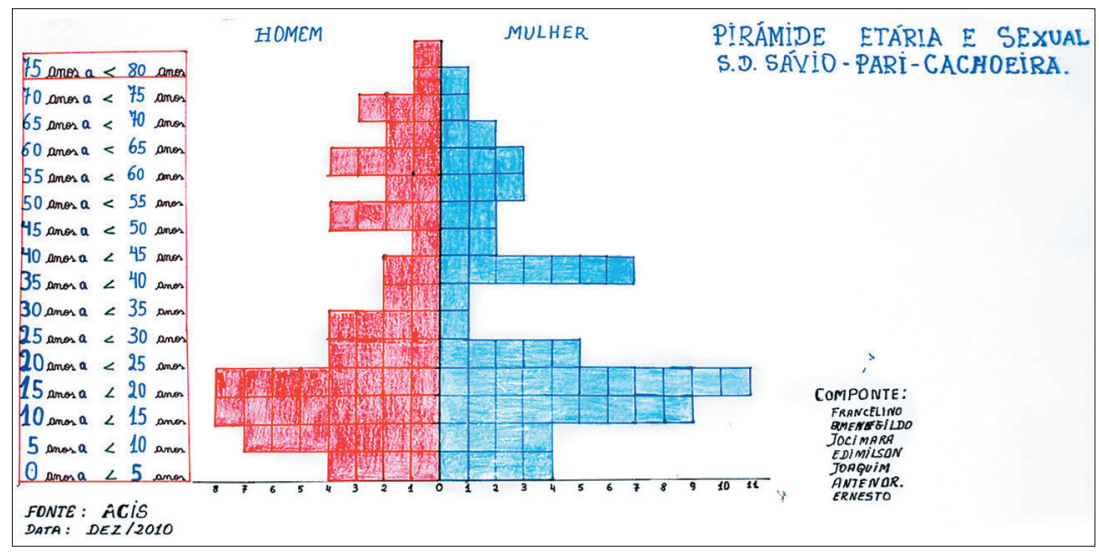

Acervo CTACIS (2009-2015).

Os dados epidemiológicos dessa população são escassos em virtude do fato que o Sistema de Informações da Atenção à Saúde Indígena (Siasi) ainda não foi plenamente implementado, e seus dados não são disponibilizados para consulta. Assim, para analisarmos a situação de saúde da população indígena infantil, somente pudemos contar com estudos dispersos realizados em alguns grupos étnicos e, destacadamente, o I Inquérito Nacional de Saúde e Nutrição dos Povos Indígenas, finalizado em 2009.

Basta, Orellana e Arantes (2012) apontam altos coeficientes de mortalidade infantil (CMI) que, apesar de uma redução nos últimos anos, ainda apresentavam média de 4I,9 por cem mil nascidos vivos e ultrapassavam cem por mil nascidos vivos em alguns grupos étnicos. Esse quadro revela a heterogeneidade e gravidade da situação de saúde das populações indígenas, pois a média nacional em 2006 era 25, I por mil nascidos vivos (Basta, Orellana $\varepsilon$ Arantes, 20I2). Os autores também destacam que no período entre 2003 e 2006 as principais causas de mortalidade infantil entre crianças indígenas foram 
as doenças do aparelho respiratório, as causas mal definidas, as doenças infecciosas e parasitárias e as afecções originadas no período perinatal. Vale destacar que as pneumonias são mencionadas como principal causa de consultas, internações e óbitos de crianças menores de 5 anos. Ademais, agravando a situação de vulnerabilidade das crianças, existe uma alta prevalência de desnutrição crônica, superior à das crianças não indígenas.

Observa-se também que $70 \%$ das causas de mortalidade infantil ocorreram no período pós-neonatal (entre 28 e 364 dias após o nascimento), o que indica problemas associados às más condições de vida, às mortes por causas evitáveis e às falhas no acesso e resolutividade das ações de APS (Basta, Orellana \& Arantes, 2012). São conclusões condizentes com a carência de sistemas de saneamento e de fornecimento adequado de água potável nas comunidades indígenas.

O I Inquérito Nacional de Saúde e Nutrição dos Povos Indígenas teve como um dos objetivos descrever a situação nutricional e alimentar e outros fatores determinantes da saúde das crianças indígenas menores de 5 anos nas quatro macrorregiões do país. Com relação à situação nutricional, identificaram uma prevalência de 5,9\% de peso baixo para idade, $25,7 \%$ de estatura baixa para a idade e 1,3\% de peso baixo para a estatura (Horta et al., 2013). O primeiro indicador nos apresenta um panorama da desnutrição aguda, o segundo da desnutrição crônica e o terceiro o efeito das perdas de peso no crescimento das crianças. Os dois primeiros indicadores foram maiores entre as crianças indígenas da região Norte, com 1 I,4\% e 40, 8 \% das crianças com baixo peso para idade e baixa estatura para idade (Horta et al., 2013).

Das crianças entrevistadas no I Inquérito, 23,5\% haviam tido sintomas de diarreia na última semana, percentual maior na região Norte, com frequência de 38, 1 \% (Escobar et al., 2015). A maior frequência de diarreia foi encontrada na faixa etária entre 6 e 23 meses, com 35,9\% dos casos (Escobar et al., 2015). Das crianças com episódios de diarreia, a pesquisa identificou que somente $55,9 \%$ receberam soro de reidratação oral. Com relação às infecções respiratórias agudas (IRA), a prevalência de tosse, congestão nasal, pneumonia e pneumonia com febre foi de 44,4\%, 31\%, 2,63\% e I,28\% (Cardoso et al., 20 I 5), sendo mais frequente nas crianças vivendo nas regiões Sul, Sudeste e Norte. Observou-se também que 19\% das crianças haviam sido hospitalizadas no último ano, sendo as principais causas a diarreia e as IRA. Esses dados apontam para a necessidade de fortalecimento das ações de saúde no âmbito da APS, e principalmente dos fatores que influenciam o estado nutricional e alimentar dessas crianças, e das estratégias de atendimento das crianças com queixas de IRA e diarreia.

Entretanto, se poucos dados são disponíveis sobre a situação de saúde das crianças indígenas, existe ainda menos conhecimento sobre o contexto da infância indíge- 
na. Temos poucas pesquisas antropológicas sobre o tema e um número ainda menor de trabalhos que abordem as especificidades dos cuidados à saúde na infância dos povos indígenas.

Na tentativa de dimensionar, minimamente, o significado dessas informações, retomaremos algumas contribuições de Clarice Cohn no seu estudo sobre as crianças xikrin (Cohn, 2000). Primeiramente, a autora enfatiza que as crianças devem ser entendidas em suas especificidades e não como "adultos em miniatura", isso significa entender a participação ativa das crianças na vida social. Essa perspectiva visa superar a ideia da criança como um receptáculo de valores, comportamentos e conhecimentos, para entendê-las como pessoas plenas (Cohn, 2000).

Essa dimensão da construção da pessoa, ou dos atributos de ser humano, deve ser analisada no interior de cada grupo social, não sendo possível fazer uma generalização entre os grupos indígenas. A construção social de pessoa se difere da concepção ocidental de indivíduo, pois não é um dado a priori, mas um constructo social contínuo (Cohn, 2000). A infância nos grupos indígenas pode representar estágios, ou parte desse processo que conforma a constituição da pessoa humana em dado grupo étnico, nos quais entram dimensões relacionadas à formação dos corpos, aos cuidados, à alimentação e à construção do parentesco.

No caso das crianças xikrin, Cohn (2000) identificou que para esse grupo étnico, as crianças nascem compostas por corpo (in) e alma (karon). Ponto de vista, por exemplo, distinto entre os guarani mbya, que, segundo Ferreira (2013), entendem que o recémnascido não possui ainda o "espírito" assentado plenamente em seu corpo, e, portanto, o pai deve confeccionar brinquedos para auxiliar nesse processo. Para os xikrin (Cohn, 2000), deve-se tomar muito cuidado com a pele do recém-nascido que, sendo "mole", não favorece a integração no corpo (in) da alma (karon).

Outra preocupação para evitar a perda do karon é que as crianças não chorem muito. Como dimensão mais característica da infância xikrin, Cohn (2000) destaca a preocupação com o desenvolvimento da faculdade de compreensão, que está associada a uma dimensão sensorial, pois "saber, conhecer, aprender, entender e compreender estão todos inseridos em suas capacidades, a de ver e ouvir” (Cohn, 2000: 200). Essa dimensão envolve orientações alimentares, uso de remédios tradicionais, entre outras práticas, por outro lado, se espera uma participação ativa da criança, demonstrando curiosidade e iniciativa.

Consideramos fundamental essa profundidade de conhecimentos sobre a perspectiva indígena de infância, pois entendemos que a atenção diferenciada no subsistema de saúde indígena se refere "não à incorporação de práticas tradicionais aos serviços 
de saúde primária, e sim como articulação entre esses e as práticas de autoatenção existentes na comunidade em particular" (Langdon, 2004: 42). Não pretendemos que os profissionais da saúde e o AIS sejam responsáveis pela implementação de cuidados tradicionais, mas indicamos que precisam ativamente se interessar, conhecer e respeitar o uso dos saberes e práticas locais.

Quando falamos em práticas de autoatenção, nos referimos a duas dimensões desse conceito proposto por Menéndez (2003), a primeira se refere aos "processos de reprodução biossocial", que envolvem os usos e cuidados corporais, as recomendações e restrições alimentares, as normas de higiene pessoal e coletiva, as regras sociais, entre outros. O segundo nível da autoatenção se refere diretamente às representações e práticas relacionadas com problemas de saúde, em sua prevenção ou cura.

$\mathrm{Na}$ abordagem curricular da saúde da criança, pretendíamos construir essa relação entre autoatenção e práticas de APS, dessa forma, no processo de desenvolvimento curricular, nos debruçamos sobre dois desafios. O primeiro se refere à abordagem sociocultural específica da infância e do cuidado à criança nas comunidades indígenas e, o segundo, à discussão e à definição dos conteúdos relativos às atribuições a serem desenvolvidas pelos AIS nas equipes.

Para definição dessas novas atribuições dos AIS, solicitou-se aos gestores e coordenações técnicas da área de saúde da criança do DSEI Alto Rio Negro os principais documentos orientadores da organização da atenção à saúde da criança. Com base nesses documentos, a coordenação do curso discutiu uma proposta curricular para o desenvolvimento do tema, tratando do seu conteúdo com profissionais e gestores locais antes da realização do curso. Dessa triagem prévia foram selecionados alguns documentos técnicos do MS e da Sesai para utilização no curso: diretrizes da Política Nacional de Atenção Integral à Saúde da Criança (Pnaisc); Cadernos de Atenção Básica, n. 33, "Acompanhamento do crescimento e desenvolvimento infantil"; documentos do Programa Nacional de Imunização; diretrizes do Atendimento Integral às Doenças Prevalentes da Infância; e documentos do Sistema de Vigilância Alimentar e Nutricional (Sisvan) e Sisvan indígena. Também foi fundamental nesse momento o envolvimento maior dos profissionais da saúde do DSEIRN na docência. Assim, médicos, odontólogos e enfermeiros do DSEl atuaram ativamente na elaboração dos planos de aula, produção de materiais didáticos e condução das atividades didáticas.

Para darmos conta das dimensões socioculturais da infância e aspectos relativos à autoatenção foi essencial termos antropólogos na equipe de coordenação do curso e no corpo docente acompanhando a construção e implementação do plano de aulas. 
Considerando que a maior parte do corpo docente nesse momento era formada por profissionais da saúde, a atuação desses antropólogos era fundamental para provocar reflexões e intervenções nas atividades didáticas sobre a problemática da implementação da atenção diferenciada.

\section{Implementação curricular dos componentes relativos à saúde da criança indígena no CTACIS}

Apresentamos a abordagem curricular do cuidado à criança indígena no CTACIS com base na escolha de momentos privilegiados dos cinco diferentes polos formativos, num ordenamento seguido nas aulas. Em termos de caracterização geral, o componente relativo à saúde da criança indígena ocupou o correspondente a cerca de 120 horas de atividades presenciais, abordando as seguintes temáticas:

- Fases da vida e cuidados na perspectiva indígena.

- Caracterização e diagnóstico da infância no território indígena.

- Priorização dos problemas na saúde da criança: comunidade, AlS e política nacional de saúde.

- Determinantes e condicionantes do crescimento e desenvolvimento saudável.

- Puericultura e cartão da criança.

- Antropometria e Sisvan: técnicas e formulários.

- Vigilância alimentar e nutricional: rotina alimentar, alimentos disponíveis e construção de orientações.

- Aleitamento materno.

- Bolsa Família.

- Imunização e PNI (Programa Nacional de Imunização): histórico, conceitos, doenças imunopreveníveis, vacinas, calendário vacinal, trabalho da equipe e do AIS.

- Adoecimento infantil: situação no ARN, doenças prevalentes, condicionantes e determinantes do adoecimento, Atenção Integrada às Doenças Prevalentes na Infância (AIDPI) (sinais de perigo, tosse, febre, diarreia, dor de ouvido)

- Organização das rotinas e das visitas domiciliares do AIS no âmbito da saúde da criança. 
Selecionamos para este capítulo alguns conteúdos e estratégias metodológicas que permitem ilustrar como abordamos as dimensões socioculturais da infância e das práticas de autoatenção no cuidado das crianças nas comunidades indígenas e a construção das atribuições profissionais em saúde para os AIS na sua atuação como membros da equipe multidisciplinar em saúde.

Conforme apontamos anteriormente, as fases da vida são construções socioculturais, de modo que o primeiro desafio para abordagem da saúde da criança foi a identificação e caracterização dessa fase. Esse trabalho de mapeamento das fases da vida foi subdividido em cada polo formativo de acordo com a diversidade étnico-linguística dos alunos. De maneira geral, realizamos uma pesquisa local que envolveu coleta e sistematização de informações acerca das características de cada fase da vida, os nomes em língua indígena e os cuidados requeridos nesses momentos da vida.

As fontes utilizadas para captar essas informações eram os próprios alunos, entrevistas com moradores das comunidades indígenas onde o curso era realizado e conversas coletivas com velhos conhecedores das tradições que eram convidados para as aulas. Os alunos inicialmente preparavam uma sistematização inicial em grupos, segundo pertencimento étnico-linguístico. Em seguida realizavam entrevistas, para as quais havia um roteiro elaborado em conjunto com os alunos e eram aplicadas na comunidade, individualmente ou em grupo. As entrevistas eram realizadas em língua indígena e depois traduzidas para os professores e colegas. Por fim, os velhos conhecedores faziam suas narrativas sobre o tema, em língua indígena, com base em demandas geradas pelos professores, e suas falas eram traduzidas e registradas pelos alunos.

Assim, as informações eram coletadas e discutidas de forma a identificarmos as diferenças entre os grupos étnicos, comentadas pelos velhos conhecedores. Podemos dizer que, ao fim desse processo, coletávamos informações profundas e específicas para cada grupo étnico sobre a fase denominada de infância. Encontramos diversas especificidades que precisam ser consideradas na organização do trabalho da equipe multiprofissional em saúde indígena.

Em termos de resultados gerais, levantaram-se práticas preventivas e curativas tradicionais, benzimentos, orientações dietéticas, resguardos, práticas de higiene, entre outros. Também identificamos os riscos e doenças às quais as crianças estão mais vulneráveis, e dimensões do cuidado familiar e comunitário com as crianças. A seguir apresentamos algumas sínteses de informações coletadas (Quadros 4 e 5). 
Quadro 4 - Descrição das fases da vida, de acordo com o grupo de AIS, do Polo Alto e Médio Içana e Aiari, subgrupo da etnia baniwa, versão em português

\begin{tabular}{|c|c|c|c|}
\hline \multicolumn{4}{|c|}{ Polo-base Tucumã - Exercícios 5 e 6} \\
\hline Nome da fase & $\begin{array}{l}\text { Características } \\
\text { das pessoas } \\
\text { nesta fase }\end{array}$ & $\begin{array}{l}\text { Faixa } \\
\text { etária }\end{array}$ & Cuidados com a saúde e a alimentação \\
\hline Gravidez/gestante & $\begin{array}{l}\text { Criança na } \\
\text { barriga }\end{array}$ & $\begin{array}{l}\text { Antes } \\
\text { de } \\
\text { nascer }\end{array}$ & $\begin{array}{l}\text { O que a mãe não pode comer durante } \\
\text { a gravidez: acutiuaia, tatu, jabuti, } \\
\text { tamanduazinho e yamaro. (Grifo dos alunos) } \\
\text { O que pode comer: sarapó pintado, pirapucu, } \\
\text { aracu, traíra, calango e remédio kodipere. } \\
\text { (Grifo dos alunos) }\end{array}$ \\
\hline Bebê & $\begin{array}{l}\text { O que mama o } \\
\text { leite da mãe, o } \\
\text { que já se senta, } \\
\text { o que engatinha. }\end{array}$ & $\begin{array}{l}0 \text { a } 1 \\
\text { ano }\end{array}$ & $\begin{array}{l}\text { Antes de dar a primeira comida é preciso } \\
\text { benzimento. } \\
\text { Depois do benzimento, o bebê pode comer: } \\
\text { mingau de maçoca e piaba. }\end{array}$ \\
\hline Criança & $\begin{array}{l}\text { O que já anda, o } \\
\text { que já brinca, o } \\
\text { que já cuida do } \\
\text { seu irmãozinho. }\end{array}$ & $\begin{array}{l}\text { I a } 5 \\
\text { anos }\end{array}$ & Já come tudo: fruta, peixes e caças \\
\hline Criança crescida & $\begin{array}{l}\text { O que já sabe } \\
\text { pescar, o que } \\
\text { ajuda o pai e a } \\
\text { mãe. }\end{array}$ & $\begin{array}{l}6 \text { a } 12 \\
\text { anos }\end{array}$ & Já come tudo. \\
\hline Rapaz ou moça & $\begin{array}{l}\text { Formação já } \\
\text { completa }\end{array}$ & $\begin{array}{l}12 \text { a } 15 \\
\text { anos }\end{array}$ & $\begin{array}{l}\text { O rapaz come tudo; a moça só come o que é } \\
\text { orientado. }\end{array}$ \\
\hline Adulto & $\begin{array}{l}\text { O que já tem seu } \\
\text { pensamento bom } \\
\text { para criar seus } \\
\text { filhos. }\end{array}$ & $\begin{array}{l}16 \text { a } 45 \\
\text { anos }\end{array}$ & Não tem mais problema de alimentação. \\
\hline Adulto & $\begin{array}{l}\text { O que já tem } \\
\text { genro e neto } \\
\text { e já recebe o } \\
\text { benefício que o } \\
\text { governo oferece. }\end{array}$ & $\begin{array}{l}45 \text { a } 60 \\
\text { anos }\end{array}$ & Não tem mais problema de alimentação. \\
\hline Idoso & $\begin{array}{l}\text { O que já anda } \\
\text { com vara na mão } \\
\text { para se apoiar. }\end{array}$ & $\begin{array}{l}\text { Mais de } \\
60 \text { anos }\end{array}$ & Não tem mais problema de alimentação. \\
\hline
\end{tabular}

Acervo CTACIS (2009-2015). 
Quadro 5 - Nomes das fases da vida segundo os grupos étnicos do Polo Formativo do Baixo Rio Negro

\begin{tabular}{|c|c|c|c|}
\hline $\begin{array}{l}0 \text { a I ano - criança } \\
\text { pequena } \\
\text { Taina Mirim } \\
\text { (nheengatu) } \\
\text { Imagł } \\
\text { (Tukano) } \\
\text { Dânteé Piís } \\
\text { (dow hupda) } \\
\text { Queramo } \\
\text { (baniwa) }\end{array}$ & $\begin{array}{l}\text { I a } 5 \text { anos - criança } \\
\text { Taina } \\
\text { (nheengatu) } \\
\text { Imag甘 } \\
\text { (tukano) } \\
\text { Dâw Teé } \\
\text { (dow hupda) } \\
\text { Queramo } \\
\text { (baniwa) }\end{array}$ & $\begin{array}{l}6 \text { a I } 2 \text { anos - rapaz } \\
\text { ou moça } \\
\text { Taina, Curumim } \\
\text { ou Cunhatã } \\
\text { (nheengatu) } \\
\text { Dawtee Pêeg } \\
\text { (dow hupda) } \\
\text { Waparo } \\
\text { (baniwa) }\end{array}$ & $\begin{array}{l}\text { I } 2 \text { a I } 5 \text { anos - jovem } \\
\text { ou adolescente } \\
\text { Pisasú kurimiasu, } \\
\text { Pisasú kunhamuku } \\
\text { (nheengatu) } \\
\text { Mamu } \\
\text { (tukano) } \\
\text { Daw Pêeg Scaaw } \\
\text { (dow hupda) } \\
\text { Waliparo } \\
\text { (baniwa) }\end{array}$ \\
\hline $\begin{array}{l}\text { I6 a } 45 \text { anos - adulto } \\
\text { Tuiu } \\
\text { (nheengatu) } \\
\text { Buhkt/ Buhktto } \\
\text { (tukano) } \\
\text { Dâw Kâan } \\
\text { (dow hupda) } \\
\text { Pedalia } \\
\text { (baniwa) }\end{array}$ & $\begin{array}{l}45 \text { anos a } 60 \text { anos - } \\
\text { velho } \\
\text { Tuiu } \\
\text { (nheengatu) } \\
\text { Buhktt/ Buhktto } \\
\text { (tukano) } \\
\text { Dâw Kâan } \\
\text { (dow hupda) } \\
\text { Pedalia } \\
\text { (baniwa) }\end{array}$ & $\begin{array}{l}\text { Mais de } 60 \text { anos - } \\
\text { velho } \\
\text { Tuiuwé } \\
\text { (nheengatu) } \\
\text { Buhktt/Buhktto } \\
\text { (tukano) } \\
\text { Dâw Kâan } \\
\text { (dow hupda) } \\
\text { Pedalia } \\
\text { (baniwa) }\end{array}$ & \\
\hline
\end{tabular}

Acervo CTACIS (2009-20I5).

Para explicar essas atividades, apresentaram-se as definições e classificações das fases da vida no mundo ocidental, portanto, observa-se, no Quadro 4, que o roteiro utilizado induziu a delimitação em faixas etárias, que não equivalem à forma de descrição das fases da vida no mundo indígena rio-negrino. Somente por ocasião do levantamento das designações nativas para as fases da vida foi possível observar que essas eram classificadas de modo diferente do que habitualmente se usa no campo da saúde, conforme se observa no Quadro 5. Além disso, a delimitação de cada fase feita pelos estudantes evidenciou que os marcadores de cada uma delas envolvem tanto características biológicas quanto sociais; estas últimas claramente relacionadas ao desenvolvimento (ou perda) de habilidades sociais que cada pessoa vai construindo (ou perdendo) ao longo da vida.

Todos os grupos foram capazes de identificar uma série de práticas de autoatenção específicas por etnia em cada momento da vida. Uma estratégia importante para identificar 
e reconhecer as concepções próprias de cada grupo étnico sobre a autoatenção consistiu em propor aos discentes que identificassem e explicassem, em língua indígena, palavras que expressassem as noções de cuidado e suas dimensões de assistência, promoção e prevenção, conforme apresentado no Quadro 6. Em caso de inexistência de noção equivalente, os estudantes foram orientados a construir o conceito em língua indígena.

\section{Quadro 6 - Construção de conceitos sobre cuidado Polo Alto e Médio Rio Içana, subgrupo Koripaco}

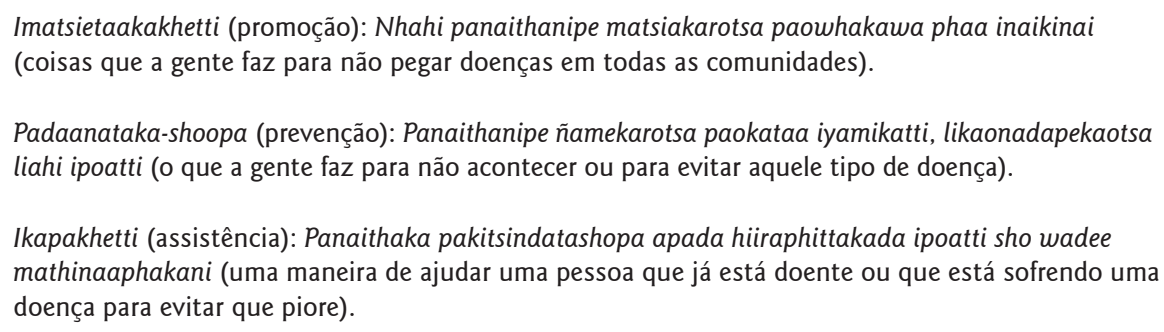

Acervo CTACIS (2009-2015).

As informações sobre cuidados na infância foram obtidas em diferentes densidades, de acordo com a possibilidade de se contar com a presença de conhecedores locais e com o conhecimento prévio dos alunos. Esses relatos eram feitos em língua indígena, e traduzidos pelos alunos para o corpo docente. Para exemplificar, um pequeno trecho de informação apresentada no curso em língua indígena e traduzida por um aluno durante as atividades do Polo Alto e Médio Içana e Aiari:

Ele [o conhecedor tradicional] falou sobre que cuidado pode ser dado às crianças, e falou sobre a formação dos seres para nós baniwa. No início o mundo era formado por quatro pessoas: Ñapirikoli, Dzooli, Mawirikoli e Eeri. Esses foram as primeiras pessoas; nossos auós. Desde aí que começaram os cuidados. Ele disse que no começo do mundo foi Ñapirikoli que engravidou a tia dele, a Amaro; ela teve um filho chamado Kowai. E esse filho fez a mãe dele sentir muita dor. (...) Eles são nossos avôs. Ele disse do cuidado que a mulher tem que ter com seu bebê; tem que ter muito cuidado com tudo, com a comida, e com depois que tem parto. Isso tudo é para não ter doença. Desde pequeno quando o bebê nasce vem o cuidado, por isso a mãe não pode comer [certos animais] quando a criança é bem novinha. A mãe tem que se cuidar, mas o marido também. $O$ bebê não pode se alimentar logo; primeiro tem que ser amamentado. Para alimentar a criança bebezinha quando ela já começa comer algumas coisas, pode dar piaba. Só que vem processo de benzimento antes dele comer; no começo é só piaba, caldo e mandioca que pode ser dado para criança. Agora, se não obedecer às regras a doença vai acontecer mesmo. É por isso é que tem de fazer a dieta tradicional; é obrigado a fazer. (Trecho relatório Polo Formativo Alto e Médio Rio Içana e Aiari) 
Alguns desafios no desenvolvimento dessa atividade se relacionaram ao fato de que esses conhecimentos não representavam novidade para os alunos, e quando entrevistavam moradores locais, em parte em razão das diferenças étnicas, as informações levantadas podiam ser bem diferentes das experiências próprias. Além disso, a diversidade étnico-linguística da turma também dificultou o aprofundamento das discussões para todos os grupos.

As entrevistas com moradores locais sobre a saúde das crianças e as conversas com os velhos conhecedores também indicaram o entendimento indígena sobre fatores de risco e principais problemas de saúde das crianças. No intuito de reforçar que a organização do trabalho em saúde deve considerar a perspectiva da comunidade, os alunos foram solicitados a organizar uma reunião comunitária para conversar sobre a situação de saúde das crianças e os principais problemas de saúde. Eles formularam as perguntas guia para a discussão e organizaram uma refeição comunitária após a qual seria realizada a conversa com as famílias. A discussão foi conduzida em língua indígena local, sendo posteriormente traduzida para o português. Apresentamos a seguir as perguntas e respostas da atividade (Quadro 7) desenvolvida no Polo Formativo Rio Xié, Baixo Rio Içana e Alto Rio Negro:

\section{Quadro 7 - Perguntas e respostas de comunidade sobre saúde das crianças}

O que as crianças precisam para crescer bem, com saúde?

Não deixar a criança suja. Não deixar a criança passar fome. Ela tem que estar bem alimentada, mas também não pode dar comida demais. Tem que diferenciar a comida da criança daquela do adulto, ou seja, fazer comida separada. A panela da comida tem que estar tampada. Uma questão importante é que as vezes a mãe vai para roça e é a irmã ou irmão mais velho que fica em casa cuidando; aí a criança pequena não se alimenta bem.

Como está a alimentação das crianças da comunidade? Elas têm boa alimentação?

Tem falta de peixe, mas nunca falta farinha e beiju. Às vezes tem almoço, mas não tem jantar. Falaram ainda que não é possível comparar a dieta e as refeições que se fazem na cidade com o que acontece na comunidade, por conta da diferença de alimentos e dos horários de comer. Entendem que o leite materno é saudável, mas a introdução do leite industrializado dá uma certa fraqueza; como prova alegam que as doenças começam a aparecer quando a criança muda do leite materno para o leite em pó comprado na cidade.

De que tipo de doenças as crianças mais adoecem nessa comunidade?

Diarreia, vômito, gripe e pneumonia.

O que poderia ser feito para melhorar a saúde das crianças e evitar as doenças?

Melhorar o tratamento do lixo; queimar o lixo, e fazer isso bem longe da comunidade. Cuidar das fraldas das crianças.

Acervo CTACIS (2009-20I5). 
Os alunos desenvolveram bem essa atividade, no geral, e relataram como aspecto positivo e novo a possibilidade de realizar uma atividade comunitária para escutar os moradores. Ao longo das atividades do curso, foi possível perceber que os AIS tendem a aprender sobre as práticas educativas observando os demais profissionais da saúde das equipes. Porém, o mais comum é que os demais profissionais da saúde se limitem a realizar palestras nas quais prevalece uma perspectiva biomédica e uma pedagogia de transmissão de conhecimentos.

Destacamos alguns aspectos das respostas da reunião comunitária apresentada no Quadro 7. O primeiro é que o tema da higiene foi recorrente. Essa preocupação é compartilhada por indígenas e ocidentais, ainda que cada uma dessas sociedades desenvolva concepções, regras, valores e significados próprios, subjacentes à questão da higiene. Numa perspectiva crítica, precisamos considerar que o higienismo é uma das práticas mais consolidadas na saúde pública e na educação em saúde, e que desde os primeiros postos do Serviço de Proteção ao Índio (SPI), a preocupação dos não indígenas com a higiene dos indígenas tem sido recorrente e persistente nas diferentes iniciativas de atuação do Estado junto a esses povos, de forma que eles já reproduzem o discurso higienista entre si e com os brancos. Entretanto, recomendações como a de manter as panelas tampadas não se devem, na perspectiva rio-negrina, à preocupação com contaminação por microrganismos e sim à prevenção contra feitiçarias.

Outro ponto a destacarmos dessas conversas comunitárias é a importância de reconhecermos que as práticas alimentares são distintas em termos de horários e regularidade nas comunidades indígenas. Na região do Alto Rio Negro é comum observarmos uma frequência de refeições reduzida em comparação com a do meio urbano; trata-se de um ritmo alimentar congruente com a jornada rural de trabalho. Isso não contradiz o fato de os indígenas comumente relatarem períodos de carência alimentar. Também destacamos que a própria noção de família é diferente da urbana, e que, portanto, a responsabilidade pelos cuidados das crianças envolve mais pessoas do que ocorre nas famílias nucleares.

Por meio dessas atividades, exercitamos a escuta das narrativas indígenas sobre a infância e cuidados com as crianças e observamos detalhes e características que variam em cada região. Essas experiências reforçaram na equipe de professores a importância de se levar em conta as práticas de autoatenção para organizar, de forma complementar, as ações de saúde realizadas pelos AIS em consonância com outros membros da equipe multidisciplinar.

A atividade da reunião comunitária serviu também para debatermos sobre o processo de definição de prioridades no trabalho em saúde. Utilizando o exemplo do 
Quadro 7, destacamos que aquela comunidade priorizou como solução para os problemas de saúde a melhoria da coleta de lixo, e as equipes multidisciplinares tendiam a não incluir esse ponto como prioridade de ação naquela região.

Os AIS também foram questionados sobre suas perspectivas acerca dos fatores de risco e problemas de saúde prioritários para a saúde das crianças. Numa primeira abordagem do tema, as diretrizes Pnaisc foram apresentadas como as prioridades adotadas pelos gestores e serviços de saúde. Esse debate buscava apontar a existência de diversos pontos de vista na eleição de prioridades em saúde e a importância de envolver os diferentes atores e na definição e organização das ações de saúde. Esse também foi o mote para contextualizar que o curso iria apresentar conteúdos que expressassem prioridades estabelecidas pelas políticas públicas de saúde e de APS, mas sempre em consonância com aquelas reconhecidas nas comunidades.

Ainda para aprofundar o debate sobre a infância, principalmente quanto aos aspectos sociais e o desenvolvimento infantil, utilizou-se em algumas turmas o filme Das crianças Ikpeng para o Mundo (Vídeo nas Aldeias, 200 I). Com base no debate sobre as diferenças e semelhanças das vivências apresentadas no filme, solicitava-se que os alunos escrevessem e conversassem sobre o cotidiano das crianças nas suas comunidades. Essas informações visavam construir um olhar sobre o crescimento e desenvolvimento saudável a partir do ponto de vista indígena.

Anteriormente havia sido solicitado que os estudantes desenvolvessem pesquisas acerca dos cuidados tradicionais, familiares e comunitários na infância, em suas comunidades de residência durante a fase de dispersão. Tais informações foram retomadas para subsidiar a discussão sobre saúde da criança. Os produtos de pesquisa dos estudantes deixaram evidente a existência de um enorme conjunto de cuidados tradicionais dirigidos às crianças. Esses resultados foram discutidos com os AIS, estimulando-os a valorizar tal conjunto de conhecimentos e práticas locais, bem como a apresentar alguns deles aos demais membros da equipe multidisciplinar que atua no DSEI.

A partir dessa contextualização da infância indígena e dos cuidados tradicionais, discutiu-se sobre os cuidados à infância realizados nos serviços de saúde do DSEl. O primeiro tema abordado foi a puericultura entendida como o acompanhamento do crescimento e desenvolvimento da criança. A principal ação de puericultura que se considerou compatível com o perfil de atuação dos AIS foi o monitoramento do peso e estatura (antropometria) para realizar a avaliação nutricional das crianças (vigilância alimentar e nutricional), além do acompanhamento do aprazamento vacinal.

Os conceitos e técnicas relativos à antropometria e à vigilância nutricional foram discutidos com os alunos por meio de vídeos, aulas expositivas e leitura de textos. 
Além da dimensão teórica, foram realizadas aulas demonstrativas, e em seguida, aulas práticas na comunidade acerca das técnicas de aferição do peso e comprimento/estatura das crianças, preenchimento das curvas antropométricas do cartão/caderneta da criança, classificação nutricional e preenchimentos dos formulários do Sisvan. Para as aulas desses conteúdos, contamos com a participação de enfermeiros e nutricionista do DSEI Alto Rio Negro, pois desejávamos que os AIS conhecessem melhor esses profissionais e obtivessem as mesmas recomendações dos demais membros das equipes.

Os AIS puderam praticar essas atividades em mutirões nas comunidades onde ocorriam as aulas do curso. Essas atividades foram entendidas como oportunidade de treinamento prático, mas tiveram também a finalidade de demonstrar para os comunitários as novas atribuições dos AIS. O preenchimento do cartão/caderneta da criança e mapa diário do Sisvan eram exercitados regularmente, para que progressivamente ganhassem confiança e habilidade no manejo deles.

Outra estratégia didática por meio da qual se verificava com facilidade a consolidação dos novos conhecimentos eram as dramatizações, nas quais os AIS eram solicitados a simular os procedimentos aprendidos. Os resultados eram comentados pelos colegas e professores. As dramatizações também eram momentos ricos para a apreensão das posturas e dimensões relacionais dos AIS com os demais membros das equipes e com a comunidade.

No decorrer da abordagem desses conteúdos, foram entregues para os AIS fitas métricas, antropômetros e balanças. Os materiais impressos como cartão/caderneta da criança e fichas do Sisvan foram distribuídos para uso em sala de aula, porém seu fornecimento era de responsabilidade do DSEIRN, o que não ocorreu com a regularidade necessária. Tal circunstância obrigou o curso a ofertar os impressos para o desenvolvimento dessas atividades na comunidade nas fases de dispersão.

Consideramos importante informar que atenção especial precisou ser dada ao cálculo da idade em anos, meses e dias de vida das crianças. Essa tarefa envolveu o reconhecimento de que, naquele contexto cultural, esse tipo de informação não tem importância na vida social cotidiana, dificultando o domínio do assunto pelos estudantes. Muitos exercícios para treinamento do cálculo da idade das crianças foram necessários para consolidar o aprendizado. Constatou-se também que a atividade exigia destreza na realização de operações aritméticas, tornando-se necessária uma suplementação de aulas de matemática, o que foi feito pelos professores indígenas das comunidadessede do curso. Com o tempo, os AIS foram se familiarizando e ganhando confiança na realização dos cálculos. 
Outra dimensão importante da puericultura era a vigilância alimentar, e, considerando que a alimentação é uma prática cultural específica, para se discutir as recomendações alimentares a serem desenvolvidas pelos AIS, houve a necessidade de coletar informações sobre oferta, disponibilidade, produção de alimentos e acesso a alimentos industrializados. Esse trabalho, realizado em momento anterior no âmbito da temática de vigilância alimentar e nutricional, foi retomado nas discussões sobre cuidado à saúde da criança e complementado com outras informações específicas necessárias.

Como exemplo podemos citar o produto de entrevistas com mulheres sobre amamentação e alimentação das crianças menores de 5 anos. As respostas demonstraram que as recomendações do MS e da Sesai precisam ser especificadas em cada contexto indígena. As orientações alimentares para as crianças precisam ser construídas localmente, pois a disponibilidade e oferta alimentar diferem em cada comunidade, assim como as regras sobre alimentação infantil, regularidade e frequência de consumo. Também é importante salientar que as mulheres naquela região não relataram problemas com amamentação, e foram ressaltados, pelas informantes indígenas, diversos cuidados e orientações alimentares que as mães devem seguir nesse período. A abordagem da amamentação precisa ser diferente daquela adotada em contexto urbano.

Considerando estudos prévios sobre perfil nutricional das crianças disponíveis para a região do Alto Rio Negro, tínhamos a preocupação de abordar dois problemas nutricionais recorrentes: o baixo peso/desnutrição e a desidratação/diarreia. A equipe discutiu muito sobre como abordar essas temáticas, uma vez que já tinham sido tratadas em diversos treinamentos anteriores, gerando a reclamação contra a repetição de assuntos. Assim, optou-se por não reprisar conteúdos já trabalhados e focar a discussão nos desafios relacionados à abordagem desses problemas no trabalho cotidiano dos AIS.

Com relação à temática da desnutrição/baixo peso, percebemos que o desafio era a construção da ideia de que o baixo peso/desnutrição - tão recorrente que se torna socialmente invisível - deveria ser tomado como problema de saúde. Antes do curso, os dados de acompanhamento de peso eram preenchidos no cartão/caderneta da criança e no mapa diário do Sisvan pelos enfermeiros; como esses dados não eram discutidos com os AIS, estes não tinham acesso a tais diagnósticos. O aprendizado das técnicas de classificação da situação nutricional permitiu que os AIS identificassem que o problema do baixo peso/desnutrição existia nas suas comunidades. A constatação da abrangência desse problema deixou os AIS muito mobilizados, principalmente em relação a detectar suas causas e preveni-las. Ao fim, esses profissionais estavam muito motivados para a realização da pesagem, medida de comprimento/estatura e classificação nutricional das crianças, mas durante todo o processo identificaram dificuldades em compreender 
e discutir com as comunidades os motivos que justificavam a necessidade de tomada mensal dessas medidas. A importância da regularidade na aferição antropométrica era assunto constante nas aulas, e concluiu-se que as estratégias deveriam ser adequadas para cada contexto local.

Com relação à diarreia, um dos problemas mais frequentes nas crianças, percebemos que a ênfase deveria ser dada na avaliação da gravidade da desidratação e no desenvolvimento de estratégias mais claras sobre como abordar cada caso. Os estudantes tinham uma ideia abrangente sobre diarreia e desidratação, mas tinham dificuldade em distinguir entre graus de gravidade da desidratação e em tomar medidas de correção. O eixo guia do debate sobre esse tema foram as recomendações da Secretaria de Vigilância em Saúde no cartaz "Manejo do paciente com diarreia" (Disponível em: <http://bvsms.saude.gov.br/bvs/cartazes/manejo_paciente_diarreia_ cartaz.pdf $>$ ), adotado pelo DSEIRN. Esse plano de manejo da diarreia propõe quatro passos denominados "observe", "explore", "decida" e "trate"; e, para proceder à classificação da gravidade da diarreia, utiliza as seguintes classificações "não tem sinais de desidratação", "tem desidratação" e "tem desidratação”. Com base nessa classificação, implementa-se um plano adaptado para os AIS, conforme indicado no Quadro 8.

\section{Quadro 8 - Síntese do “Manejo do paciente com diarreia” adaptado para os AIS}

\begin{tabular}{|l|l|l|}
\hline Plano A & Plano B & Plano C \\
\hline $\begin{array}{l}\text { Criança com diarreia sem } \\
\text { desidratação }\end{array}$ & $\begin{array}{l}\text { Criança com diarreia e } \\
\text { desidratação }\end{array}$ & $\begin{array}{l}\text { Criança com diarreia e } \\
\text { desidratação grave }\end{array}$ \\
\hline $\begin{array}{l}\text { Ensinar o responsável a } \\
\text { reconhecer os sinais de } \\
\text { desidratação e recomendar } \\
\text { que, em caso de piora, inicie } \\
\text { a administração de SRO e } \\
\text { procure novamente o AIS. }\end{array}$ & $\begin{array}{l}\text { A criança com desidratação } \\
\text { deverá permanecer no } \\
\text { polo-base ou sob observação } \\
\text { do AIS até a reidratação } \\
\text { completa e retornar para } \\
\text { reavaliação, após 24 a 48 } \\
\text { horas, ou imediatamente, } \\
\text { em caso de piora. }\end{array}$ & $\begin{array}{l}\text { A criança deve ficar recebendo } \\
\text { SRO sob observação do AIS e } \\
\text { solicitar com urgência remoção } \\
\text { para o polo-base ou serviço } \\
\text { mais próximo para receber } \\
\text { reidratação parenteral. }\end{array}$ \\
\hline
\end{tabular}

Acervo CTACIS (2009-20I5).

Realizaram-se discussões de casos em sala de aula para fixar os critérios e condutas para as diferentes classificações de risco. Por fim, as informações levantadas e discutidas com os alunos e os profissionais do DSEIRN sobre desnutrição/baixo peso permitiram a construção de um conjunto de condutas orientadoras da atuação do AIS, apresentadas no Quadro 9. 


\section{Quadro 9 - Condutas para a criança com problemas nutricionais}

\begin{tabular}{|c|c|c|}
\hline Problema & Conduta Nutricional & Conduta Alimentar \\
\hline $\begin{array}{l}\text { Criança com } \\
\text { baixo peso } \\
\text { sem diarreia }\end{array}$ & $\begin{array}{l}\text { - Pesar e medir a criança de } 15 \text { em } 15 \\
\text { dias; } \\
\text { - Fazer o registro das medidas da } \\
\text { criança no cartão da criança e Sisvan; } \\
\text { - Comparar com as medidas anteriores. } \\
\text { Ver a curva que está no cartão para } \\
\text { avaliar se a criança está melhorando } \\
\text { ou piorando; } \\
\text { - Mostrar para a família os resultados } \\
\text { da avaliação e pedir reforço alimentar; } \\
\text { - Resultado positivo: animar a família } \\
\text { para continuar; } \\
\text { - Resultado negativo: adotar conduta } \\
\text { alimentar; } \\
\text { - Preencher a "Ficha de monitoramento } \\
\text { da criança de } 0 \text { a } 59 \text { meses com } \\
\text { problemas nutricionais". }\end{array}$ & $\begin{array}{l}\text { Para assistência alimentar à criança } \\
\text { desnutrida e de baixo peso } \\
\text { - O AIS deve orientar as mães e pais a } \\
\text { reforçar a quantidade de proteínas, } \\
\text { vitaminas e sais minerais da comida } \\
\text { das crianças desnutridas e com baixo } \\
\text { peso. } \\
\text { Para prevenção dos problemas } \\
\text { nutricionais } \\
\text { - Explicar para a família e para a } \\
\text { comunidade sobre os problemas } \\
\text { nutricionais existentes no território e } \\
\text { orientar a respeito dos nutrientes que } \\
\text { existem nos alimentos tradicionais } \\
\text { e dos problemas gerados pelos } \\
\text { alimentos industrializados. } \\
\text { - Fazer levantamento da alimentação } \\
\text { de cada família e da comunidade para } \\
\text { verificar o consumo de alimentos no } \\
\text { cotidiano. Neste levantamento, o } \\
\text { AIS deve procurar saber que tipos de } \\
\text { nutrientes são consumidos todos os } \\
\text { dias; quais são consumidos só de vez } \\
\text { em quando; e quais estão faltando } \\
\text { na dieta, conforme o território da } \\
\text { comunidade. } \\
\text { - Caso a comunidade aceite, cada } \\
\text { família poderia ter um terreno } \\
\text { específico para a produção de } \\
\text { alimentos, de modo a reforçar a } \\
\text { oferta de vitaminas, sais minerais e } \\
\text { proteínas para seus filhos pequenos. } \\
\text { O AIS também pode estimular a } \\
\text { rotação de colheitas para facilitar o } \\
\text { consumo de todos os nutrientes ao } \\
\text { longo do ano, priorizando as crianças } \\
\text { com baixo peso e desnutriccaao. }\end{array}$ \\
\hline
\end{tabular}


Quadro 9 - Condutas para a criança com problemas nutricionais (continuação)

\begin{tabular}{|c|c|c|}
\hline Problema & Conduta Nutricional & Conduta Alimentar \\
\hline $\begin{array}{l}\text { Criança com } \\
\text { baixo peso e } \\
\text { com diarreia }\end{array}$ & $\begin{array}{l}\text { - Pesar e medir a criança de } 15 \text { em } 15 \\
\text { dias, com acompanhamento diário da } \\
\text { evolução da diarreia e do peso (seguir } \\
\text { o roteiro "Avaliação da criança com } \\
\text { diarreia"); } \\
\text { - Fazer o registro das medidas da } \\
\text { criança no cartão da criança e Sisvan; } \\
\text { - Comparar com as medidas anteriores. } \\
\text { Ver a curva que está no cartão para } \\
\text { avaliar se a criança está melhorando } \\
\text { ou piorando; } \\
\text { - Mostrar para a família os resultados } \\
\text { da avaliação e pedir reforço alimentar; } \\
\text { - Fazer soro conforme "Manejo do } \\
\text { paciente com diarreia”; } \\
\text { - Resultado positivo: animar a família } \\
\text { para continuar tratamento; resultado } \\
\text { negativo: aumentar o número de } \\
\text { doses do soro oral, comunicar } \\
\text { ao polo-base e a colegas mais } \\
\text { experientes, pedir remoção e adotar } \\
\text { conduta alimentar. }\end{array}$ & $\begin{array}{l}\text { Para promoção da saúde } \\
\text { - Organizar as famílias e as } \\
\text { comunidades para melhorar a } \\
\text { qualidade e aumentar a quantidade de } \\
\text { nutrientes consumidos por crianças } \\
\text { de baixo peso, por meio de: } \\
\text { - pescaria e caçaria; } \\
\text { - criação de peixes e de galinhas; } \\
\text { - reforço à plantação de roça } \\
\text { para alimento da família e para } \\
\text { alimentar animais de criação; } \\
\text { - reforço à plantação de fruteiras, } \\
\text { na roça e na comunidade. } \\
\text { - Estimular: } \\
\text { - No verão, para as comunidades } \\
\text { de terra arenosa: a pescaria, a } \\
\text { caçaria e a plantação de caju, } \\
\text { abacaxi, coco, açaí, ingá, manga, } \\
\text { pupunha, cucura, banana e } \\
\text { pimenta. }\end{array}$ \\
\hline $\begin{array}{l}\text { Criança } \\
\text { com muito } \\
\text { baixo peso } \\
\text { (desnutrição) } \\
\text { sem diarreia }\end{array}$ & $\begin{array}{l}\text { - Pesar e medir a criança de } 7 \text { em } 7 \\
\text { dias; } \\
\text { - Fazer o registro das medidas da } \\
\text { criança no cartão da criança e Sisvan; } \\
\text { - Comparar com as medidas anteriores. } \\
\text { Ver a curva que está no cartão para } \\
\text { avaliar se a criança está melhorando } \\
\text { ou piorando; } \\
\text { - Mostrar para a família os resultados } \\
\text { da avaliação e pedir reforço alimentar; } \\
\text { - Resultado positivo: animar a família } \\
\text { para continuar; resultado negativo: } \\
\text { adotar conduta alimentar. }\end{array}$ & $\begin{array}{l}\text { de terra firme: a pescaria, a } \\
\text { caçaria e a plantação de abacaxi, } \\
\text { cará, cana, banana, abóbora, } \\
\text { cubiú, batata doce, pupunha, } \\
\text { abio, banana e pimenta. }\end{array}$ \\
\hline
\end{tabular}


Quadro 9 - Condutas para a criança com problemas nutricionais (continuação)

\begin{tabular}{|c|c|c|}
\hline Problema & Conduta Nutricional & Conduta Alimentar \\
\hline $\begin{array}{l}\text { Criança com } \\
\text { muito baixo } \\
\text { peso com } \\
\text { diarreia }\end{array}$ & $\begin{array}{l}\text { - Pesar e medir a criança de } 7 \text { em } 7 \\
\text { dias, com acompanhamento diário da } \\
\text { evolução da diarreia e do peso (seguir } \\
\text { a “Avaliação da criança com diarreia”); } \\
\text { - Fazer o registro das medidas da } \\
\text { criança no cartão da criança e Sisvan; } \\
\text { - Comparar com as medidas anteriores. } \\
\text { Ver a curva que está no cartão para } \\
\text { avaliar se a criança está melhorando } \\
\text { ou piorando; } \\
\text { - Mostrar para a família os resultados } \\
\text { da avaliação e pedir reforço alimentar; } \\
\text { - Fazer soro conforme “Condutas para } \\
\text { casos de diarreia”; } \\
\text { - Resultado positivo: animar a família } \\
\text { para continuar; resultado negativo: } \\
\text { aumentar o número de doses do } \\
\text { soro oral, comunicar ao polo-base } \\
\text { e a colegas mais experientes, pedir } \\
\text { remoção e adotar conduta alimentar. }\end{array}$ & $\begin{array}{l}\text { - No inverno, para as comunidades } \\
\text { de terra arenosa: a pescaria na } \\
\text { piracema, a caçaria e a coleta } \\
\text { na mata de buriti, açaí do mato, } \\
\text { umari e patauá. } \\
\text { - No inverno, para as comunidades } \\
\text { de terra firme: a pescaria na } \\
\text { piracema, a caçaria e a coleta, } \\
\text { na mata açaí do mato, bacaba, } \\
\text { patauá, ucuqui e umari. }\end{array}$ \\
\hline
\end{tabular}

Acervo CTACIS (2009-2015).

Devemos destacar que encontramos dificuldades para que os AIS pudessem assumir as responsabilidades sobre antropometria e vigilância nutricional das crianças. Além dos supracitados problemas com fornecimento de equipamentos e formulários pelo DSEI, houve o desafio de obter anuência dos enfermeiros e técnicos de enfermagem das equipes para dividir as tarefas de vigilância alimentar com os AIS. Percebemos que havia uma desconfiança com relação à qualidade do trabalho dos AIS, mas também pouco interesse em apoiá-los e estimulá-los para a melhoria das suas habilidades e aumento da confiança na execução dessas ações. Embora a coordenação do curso realizasse reuniões periódicas com a gerência do DSEI, com os próprios profissionais das equipes, e distribuísse os roteiros e textos utilizados nas aulas, percebemos haver uma disputa de espaço e de poder de algumas categorias profissionais que relutavam em descentralizar algumas tarefas para os AIS, sob a alegação - etnocêntrica - de que os indígenas não seriam capazes de executar atividades técnicas de saúde. Em contrapartida, uma vez familiarizados com o manejo correto das técnicas de antropometria e o preenchimento do cartão e da curva de crescimento, diversos AIS passaram a identificar erros cometidos pelos demais membros das equipes e a apontar publicamente os equívocos cometidos na realização dessas tarefas, gerando novos conflitos na relação interprofissional. 
Outro tema estratégico na organização da atenção à saúde da criança no âmbito da equipe multidisciplinar é o Programa Nacional de Imunização (PNI), visto como principal ação preventiva desenvolvida no DSEI. Para introduzir essa temática, optamos por discutir inicialmente o histórico de epidemias decorrentes do contato entre indígenas e não indígenas. Para isso, exibimos o filme Xingu (20 I I), dirigido por Cao Hamburger, que relata a trajetória dos irmãos Villas-Boas na Expedição Roncador-Xingu e a forma como nesse processo os grupos indígenas, antes isolados, sofreram várias epidemias de gripe que mataram muitos deles e desestruturaram as comunidades. Assim, o filme contextualizou e pontuou o início das atividades de vacinação nas aldeias, provocando reflexões dos alunos acerca da própria história. Para subsidiar o debate também se apresentou uma versão adaptada do texto "Contas de vidro, enfeites de branco e 'potes de malária': epidemiologia e representações de doenças infecciosas entre os desana”, de Dominique Buchillet (1995) acerca do histórico das epidemias na região do Alto Rio Negro.

Além da dimensão histórica e social do contexto das epidemias, havia a preocupação em apresentar um sumário do mecanismo de ação das vacinas e o PNI, visando subsidiar o trabalho do AIS nas atividades educativas com as comunidades. Como estratégia para essa discussão foram utilizados vídeos, imagens e leitura de texto explicativo sobre o PNI, produzido pelos professores. A leitura do texto foi repetida várias vezes no intuito de esclarecer palavras desconhecidas do acervo vocabular dos estudantes.

Como forma de apropriação do tema, os alunos foram convocados a produzir cartazes explicativos para as comunidades, em línguas indígenas, versando sobre vacinação. Essas atividades mostraram a dificuldade do processo de traduzir informações técnicas para o linguajar cotidiano. O desenvolvimento da tarefa permitiu perceber que os AIS tenderam a escolher a estratégia de aula expositiva ou palestra, com adoção de muitos termos técnicos que dificultariam a compreensão do tema pelos comunitários. Além disso, percebemos que os AIS imitaram algumas estratégias moralistas e aterrorizantes presentes nas práticas dos profissionais da saúde. Tais problemas foram devidamente sanados, mas sua ocorrência alertou a coordenação do curso para a importância de discussões mais aprofundadas sobre práticas de educação em saúde.

Pretendíamos também que os AIS aprendessem a verificar o registro vacinal no cartão/ caderneta da criança, no intuito de apoiar o restante na equipe no planejamento das atividades de vacinação e monitoramento dos atrasos vacinais. Para isso, foi explicado como deveria ser feito o registro de vacinação no cartão e apresentado o calendário vacinal específico para as crianças indígenas. Esse conteúdo foi praticado por meio da construção de calendário em cartaz conforme (Quadro I0), com campos removíveis. 
Quadro 10 - Aprazamento vacinal para crianças indígenas, normativa PNI de 2013

\begin{tabular}{|c|c|c|c|c|c|c|c|}
\hline \multicolumn{5}{|c|}{ Vacinas obrigatórias no $1^{\circ}$ ano de vida } & \multirow{2}{*}{$\begin{array}{l}\text { Febre- } \\
\text { amarela }\end{array}$} & \multicolumn{2}{|c|}{ Outras vacinas } \\
\hline Antipólio & Tetra & Hepatite B & BCG & Tríplice viral & & Rotavírus & Pneumolo \\
\hline 2 meses & 2 meses & Ao nascer & Ao nascer & $\begin{array}{l}\mathrm{I}^{\mathrm{a}} \text { dose } \\
\text { I ano }\end{array}$ & 9 meses & $\begin{array}{l}\mathrm{I}^{\mathrm{a}} \text { dose } \\
2 \text { meses }\end{array}$ & $\begin{array}{l}\mathrm{I}^{\mathrm{a}} \text { dose } \\
2 \text { meses }\end{array}$ \\
\hline 4 meses & 4 meses & $\begin{array}{l}30 \text { dias } \\
\text { após a I a } \\
\text { dose }\end{array}$ & & $\begin{array}{l}2^{\mathrm{a}} \text { dose } \\
4-6 \text { anos }\end{array}$ & $\begin{array}{l}\text { Varicela } \\
\text { I ano }\end{array}$ & $\begin{array}{l}\text { Rotavírus } \\
2^{\mathrm{a}} \text { dose } \\
4 \text { meses }\end{array}$ & $\begin{array}{l}\text { Pneumolo } \\
2^{\mathrm{a}} \text { dose } \\
4 \text { meses }\end{array}$ \\
\hline 6 meses & 6 meses & 6 meses & Gripe & & $\begin{array}{l}\text { Pneumo23 } \\
2 \text { anos }\end{array}$ & $\begin{array}{l}\text { Pneumolo } \\
\text { Reforço } \\
15 \text { meses }\end{array}$ & $\begin{array}{l}\text { Pneumo } 0 \\
3^{\text {a }} \text { dose } \\
6 \text { meses }\end{array}$ \\
\hline 15 meses & $\begin{array}{l}\text { DTP } \\
\text { I }^{\circ} \text { reforço } \\
\text { I } 5 \text { meses }\end{array}$ & $\begin{array}{l}\text { DTP } \\
2^{\circ} \text { reforço } \\
4-6 \text { anos }\end{array}$ & & & $\begin{array}{l}\text { MNGC } \\
\text { Reforço } \\
15 \text { meses }\end{array}$ & $\begin{array}{l}\text { MNGC } \\
\text { I }^{\text {a }} \text { dose } \\
3 \text { meses }\end{array}$ & $\begin{array}{l}\text { MNGC } \\
2^{a} \text { dose } \\
5 \text { meses }\end{array}$ \\
\hline
\end{tabular}

Acervo CTACIS (2009-20I5).

As rotinas de vacinação também foram dramatizadas em sala de aula para debate, pedindo-se tanto para demonstrar como foram realizadas as atividades de vacinação nas comunidades nos últimos anos quanto para levantar a opinião dos AIS sobre como deveria ser a rotina de vacinação nas comunidades e como eles poderiam atuar. Essa atividade foi extremamente rica para percebermos como costumava ser a inserção dos AIS nas equipes e quais eram as expectativas acerca de seu novo papel. Na dramatização sobre a forma como as equipes vinham atuando nas atividades de vacinação, os AIS, destacaram que essas atividades não eram pactuadas com as comunidades antecipadamente; sua realização era apressada e havia falta de material. Aos AIS eram atribuídos somente serviços gerais, como carregar caixas e organizar o espaço para o trabalho dos enfermeiros.

A seguir apresentamos o relato feito pelos alunos do Polo Rio Xié, Baixo Içana e Alto Rio Negro, que expressa as ideias dos estudantes sobre como realizar uma boa vacinação:

Primeiro a equipe passa na comunidade somente para entregar um cronograma no qual consta a data em que eles passarão naquela comunidade para fazer a vacinação. Após isso a AIS passa de casa em casa avisando a visita da equipe. Quando a equipe chega fornece os mapas Sisvan, se apresentam, a enfermeira conversa sobre a importância da vacinação. Eles se mostram disponíveis para outros problemas que as pessoas da comunidade querem tratar, dando prioridade aos pacientes graves, perguntando, por exemplo, sobre outras condições de saúde a lém da situação vacinal. A atuação do AIS foi muito importante neste grupo, ele fez 
uma boa ligação entre equipe e comunidade; também conversou com a equipe, indicando as situações mais problemáticas, falando das pessoas que estão sem vacinas e indicando quais vacinas estão faltando. (relatório curso CTACIS, polo Baixo Rio Negro).

Observa-se nesse relato que os alunos destacaram a importância da pactuação com as comunidades para o desenvolvimento das atividades, a abertura a múltiplas demandas da população e uma atuação ativa do AIS no planejamento e execução das ações de saúde.

Em razão da alta prevalência de IRA e de os dados indicarem a pneumonia como uma das principais causas de morte em crianças indígenas menores de 5 anos, consideramos fundamental abordar essa temática. Novamente, trata-se de problema de saúde muito familiar aos AIS e que já havia sido abordado em outros treinamentos. Entretanto, se observava pouca clareza sobre como identificar uma criança com suspeita de pneumonia. Dessa forma, fez-se uma abordagem ampla das IRAs, com discussão acerca das vias aéreas superiores e esclarecimento sobre as formas de transmissão e prevenção das IRAs. Os AIS foram ensinados a contar a frequência respiratória das crianças e a identificar tiragem subcostal, pois esses são os principais sinais clínicos para suspeita de pneumonia. Adotaram-se as recomendações do MS para critérios de suspeita de pneumonia e condutas para os AIS, apresentadas no Quadro II.

Quadro II - Critérios para classificar casos de IRA e suspeita de pneumonia

\begin{tabular}{|c|c|c|c|}
\hline Idade & $\begin{array}{l}\text { IRA não } \\
\text { pneumonia }\end{array}$ & Suspeita de pneumonia & Suspeita de pneumonia grave \\
\hline $\begin{array}{l}\text { Menor de } 2 \\
\text { meses }\end{array}$ & \multirow{3}{*}{$\begin{array}{l}\text { Sem tiragem } \\
\text { subcostal } \\
\text { e sem } \\
\text { respiração } \\
\text { rápida para a } \\
\text { idade }\end{array}$} & $\varnothing$ & $\begin{array}{l}\text { Respiração rápida para idade } \\
\text { ( } \geq 60 \mathrm{rpm} \text { ) e/ou tiragem } \\
\text { subcostal }\end{array}$ \\
\hline $\begin{array}{l}\text { De } 2 \text { a II } \\
\text { meses }\end{array}$ & & $\begin{array}{l}\text { Respiração rápida para idade } \\
\text { ( } \geq 50 \mathrm{rpm} \text { ) sem tiragem } \\
\text { subcostal }\end{array}$ & $\begin{array}{l}\text { Respiração rápida para } \\
\text { idade }(\geq 50 \mathrm{rpm}) \text { e tiragem } \\
\text { subcostal }\end{array}$ \\
\hline De I a 4 anos & & $\begin{array}{l}\text { Respiração rápida para idade } \\
\text { ( } \geq 40 \mathrm{rpm} \text { ) sem tiragem } \\
\text { subcostal }\end{array}$ & $\begin{array}{l}\text { Respiração rápida para } \\
\text { idade ( } \geq 40 \mathrm{rpm}) \text { e tiragem } \\
\text { subcostal }\end{array}$ \\
\hline Conduta & $\begin{array}{l}\text { Sintomáticos } \\
\text { em casa }\end{array}$ & Encaminhar ao polo-base & $\begin{array}{l}\text { Remoção imediata para } \\
\text { polo-base ou sede DSEI }\end{array}$ \\
\hline
\end{tabular}

Acervo CTACIS (2009-20I5).

O último tema que a equipe da coordenação do curso, em conjunto com profissionais e gestores do DSEIRN, inseriu na abordagem do cuidado à saúde das crianças foi a estratégia denominada Atenção Integrada às Doenças Prevalentes na Infância (AIDPI). 
Esse programa foi desenvolvido e disseminado pela OMS, e havia sido adotado pelo MS e pela Sesai. Entretanto, na implantação do AIDPI nos DSEI não houve o treinamento de todos os profissionais médicos e de enfermagem, e, principalmente, não se discutiu a inserção dos AIS. Apesar disso, considerou-se relevante a qualificação dos AIS nessa estratégia, pois na região do Alto Rio Negro, em razão das grandes distâncias e frequentes ausências dos demais membros da equipe, os AIS são o primeiro contato das crianças doentes com os serviços. São eles que fazem o primeiro atendimento e avaliação de risco das crianças, porém até aquele momento o faziam sem critérios claros e padronizados.

Para introduzir a importância do AIDPI na atuação dos AIS, inicialmente se discutiu com os alunos a situação da mortalidade infantil na região do Alto Rio Negro, cujos dados mostravam a alta prevalência de diarreia e IRA, e mortalidade elevada por pneumonia. Com base nesses dados, se problematizaram as causas da mortalidade infantil na região, levantando-se aspectos culturais, de saneamento, de cuidados familiares, de ações de saúde, de recursos territoriais, entre outros.

Como alguns médicos e enfermeiros do DSEIRN haviam sido treinados no AIDPI, um desses médicos foi incorporado na equipe do curso e, em conjunto com a coordenação, preparou uma adaptação do material do MS sobre a AIDPI para os AIS. Foram adaptadas as instruções das etapas e os formulários, de modo a facilitar a compreensão e utilização pelos AIS. A equipe fez uma simplificação e síntese da estratégia AIDPI e de seus passos da seguinte forma:

Passo I - Sinais gerais de perigo

- Não bebe ou não consegue mamar.

- Vomita tudo o que ingere.

- Apresenta ou apresentou convulsões.

- Está letárgica (molinha, não reage aos estímulos) ou inconsciente (desacordada, desmaiada).

Passo 2 -Sintoma principal: tosse

- Perguntar: há quanto tempo? Mais de 14 dias?

- Verificar: frequência respiratória, tiragem subcostal e estridor. 
PASSO 3 - Sintoma principal: diarreia

- Perguntar: há quanto tempo? Mais de 14 dias? Tem sangue?

- Verificar:

- Condição geral

- Letargia/inconsciência

- Agitação/irritação

- Olhos fundos

- Sinal da prega

- Muito lentamente

- Lentamente

- Como bebe: não bebe ou bebe com muita vontade

PAsso 4 - Sintoma principal: febre

- Perguntar: esteve nos últimos trinta dias em área de risco para malária? Está com febre há quanto tempo?

- Verificar:

- Rigidez da nuca

- Petéquias

- Fontanela abaulada

$\mathrm{Na}$ abordagem do AIDPI, o primeiro ponto foi a verificação de sinais vitais, os alunos aprenderam a verificar a frequência respiratória, pulso e temperatura, o que foi feito com demonstração e prática entre os alunos e com filhos(as) deles, quando possível. Em seguida seguimos a sequência proposta pelo próprio treinamento do AIDPI usando os vídeos disponibilizados por ele. Exibimos os vídeos em conjunto com a leitura dos roteiros produzidos, revisando várias vezes e discutindo cada ponto. Os casos apresentados nos vídeos para exercício foram fundamentais para os alunos praticarem e ganharem maior confiança. Também se desenvolveram exercícios de estudo de casos propostos pelos professores para discutir a classificação de risco das crianças, e dramatizações para verificar a apreensão dos alunos da sequência de perguntas proposta pelo AIDPI. Consideramos que, apesar das dificuldades iniciais, ao fim, os AIS tiveram um bom manejo dos formulários e das classificações do AIDPI, nos mostrando que existe a possibilidade de utilizarem ferramentas específicas do campo da saúde. 
A estratégia AIDPI também se mostrou interessante para revisar e articular os diversos conteúdos abordados como avaliação de estado nutricional e de desidratação e aprazamento vacinal. Outro ponto importante foi a padronização nos critérios e termos para a avaliação de risco das crianças, relatado como um facilitador da comunicação entre os AIS nas comunidades e os enfermeiros e médicos das equipes multidisciplinares.

Após a abordagem de todos os temas, a discussão sobre o cuidado à saúde da criança indígena foi finalizada com a discussão das novas atribuições dos AIS nesse âmbito. Durante todo o processo de discussão curricular, sempre buscamos ressignificar a visita domiciliar, pois os AIS tinham pouca clareza sobre seus objetivos, que no geral ficavam resumidos a identificar pessoas com queixas agudas. Dessa forma, a equipe de coordenação do curso se esforçou para construir roteiros de visita domiciliar para as áreas de atuação do AIS. Ao fim de cada bloco temático, se fazia a leitura e debate dos roteiros produzidos, e dramatização para se discutir a viabilidade dele. Este processo é exemplificado no fim deste capítulo pela apresentação do "Roteiro de visita domiciliar do AIS em saúde da criança", no qual focamos principalmente a vigilância alimentar e nutricional e o acompanhamento vacinal das crianças. Também se pontuaram ações a serem desenvolvidas pelos AIS no âmbito comunitário para a promoção da saúde e prevenção de doenças, e se destacaram algumas atribuições do restante da equipe multiprofissional em saúde indígena.

Para finalizar o capítulo, gostaríamos de ressaltar que esse conjunto de temas e abordagens foi possível por uma articulação próxima entre a equipe do curso e os profissionais da saúde do DSEIRN. Entretanto, apesar dessa proximidade durante o curso, em razão da alta rotatividade dos profissionais do DSEIRN, muitos dos novos profissionais das equipes e da nova gestão não mantiveram os AIS estimulados e apoiados para implementar as ações de saúde.

EXEMPLO I: ROTEIRO de VISITA DOMICILIAR DO AIS EM SAÚde DA CRIANÇA

I. "Bater na porta” e pedir autorização para entrar.

2. Cumprimentar as pessoas da casa.

3. Se for oferecido algum alimento, o AIS deve aceitar e partilhar a comida.

4. Conversar um pouco para deixar as pessoas da casa à vontade. 
5. Explicar a finalidade da visita depois do novo treinamento. Explicar também:

a) Os novos procedimentos aprendidos para fazer o acompanhamento da saúde da criança (acompanhamento do crescimento, vigilância alimentar e nutricional, vacinação e atenção integral à criança doente).

b) A necessidade de assistir aos doentes, mas que também terá que acompanhar as pessoas sadias, principalmente mulheres e crianças.

6. Para acompanhamento da saúde das crianças, o AlS deve:

- Antes do início da visita:

- Identificar quantas crianças vivem na comunidade e em cada casa, através da "Ficha A" ou do caderno de capa preta.

- Identificar quem são as crianças de 0 a 5 anos de idade, que têm prioridade para atendimento em saúde da criança.

- Antes de sair para a visita, o AIS deve separar e levar todos os materiais necessários para fazer a visita: balança, fita métrica, antropômetro, "Ficha de acompanhamento da vigilância alimentar e nutricional da criança indígena pelo AIS", fichas do Sisvan, "Formulário de registro: avaliar e classificar a criança doente", termômetro, lápis, caneta e borracha;

- Logo no início da visita o AIS deve:

- Registrar, na "Ficha de acompanhamento da vigilância alimentar e nutricional da criança indígena pelo AIS”, a data de atendimento, nome da mãe e da criança, data de nascimento, e calcular a idade;

Esses procedimentos devem ser feitos para cada criança visitada, dentro da faixa prioritária, independentemente de elas estarem doentes ou não.

EXEMPLO 2: ROTEIRO DE PROCEDIMENTOS DE AVALIAÇÃO DE CRIANÇAS NA VISITA DOMICILIAR

I. Recém-Nascidos

- Realizar visita domiciliar logo que a mãe tiver condições de levantar (no dia do parto ou dia seguinte do parto, de preferência) para:

- Verificar o peso, comprimento e perímetro encefálico (cabeça) da criança; 
- Preencher a Declaração de Nascido Vivo;

- Verificar coto umbilical e orientar os cuidados durante o primeiro mês, principalmente se houver sinais de inflamação como pus, vermelhidão e inchaço no coto umbilical ou na pele ao redor;

- Orientar sobre a importância da amamentação exclusiva até 6 meses;

- Orientar sobre o Cartão da Criança e o calendário vacinal a ser seguido. Revisar o cartão de vacina da mãe, verificando se a vacinação materna está completa;

- Orientar sobre a higiene oral da criança durante a amamentação;

- Informar o restante da equipe sobre os nascimentos, visando a realização da primeira consulta de puericultura e vacinação.

2. Crianças até 6 meses

- Realizar visita domiciliar mensal.

- Calcular a idade da criança em anos e meses (fazendo o arredondamento para o Sisvan).

- Verificar o peso e comprimento.

- Preencher (a lápis) o Cartão da Criança ou Caderneta da Criança, verificar a classificação nutricional e orientar a família para os casos de baixo peso e muito baixo peso.

- Preencher mapa mensal do Sisvan.

- Incentivar o aleitamento materno exclusivo.

- Verificar a situação vacinal e orientar sobre as próximas vacinas.

- Orientar sobre a higiene oral da criança durante a amamentação.

- Informar o restante da equipe sobre as crianças identificadas com muito baixo peso/baixo peso/risco nutricional e com atraso vacinal e encaminhar seus registros para revisão pela(o) enfermeira(o).

3. Crianças de 6 meses a I ano

- Realizar visita domiciliar mensal.

- Calcular a idade da criança em anos e meses (fazendo o arredondamento para o Sisvan). 
- Verificar o peso e comprimento.

- Preencher o Cartão da Criança ou Caderneta da Criança e verificar a classificação nutricional.

- Preencher mapa mensal do Sisvan.

- Verificar a situação vacinal e orientar sobre as próximas vacinas.

- Incentivar a continuidade da amamentação e orientar sobre a introdução de outros alimentos e a alimentação complementar.

- Orientar sobre a higiene oral da criança.

- Informar o restante da equipe sobre as crianças identificadas com muito baixo peso/baixo peso/risco nutricional e com atraso vacinal e encaminhar seus registros para revisão pela(o) enfermeira(o).

Obs.: Preste atenção redobrada ao estado nutricional da criança nesse período, pois a mudança de alimentação aumenta a vulnerabilidade.

4. Crianças de I a 5 anos

- Realizar visita domiciliar mensal.

- Calcular a idade da criança em anos e meses (fazendo o arredondamento para o Sisvan).

- Verificar o peso e altura/comprimento.

- Preencher o Cartão da Criança ou Caderneta da Criança e verificar a classificação nutricional.

- Preencher mapa mensal do Sisvan.

- Verificar a situação vacinal e orientar sobre as próximas vacinas.

- Incentivar a continuidade da amamentação até 2 anos.

- Orientar sobre a higiene oral da criança.

- Orientar sobre alimentos ricos em ferro, vitamina C, proteína e carboidratos, principalmente para as crianças com baixo peso ou muito baixo peso.

- Informar o restante da equipe sobre as crianças identificas com muito baixo peso/baixo peso/risco nutricional e com atraso vacinal e encaminhar seus registros para revisão pela(o) enfermeira(o). 
5. Para crianças com queixas

- Calcular a idade da criança em anos e meses.

- Verificar o peso e altura/comprimento.

- Verificar sinais vitais (temperatura, frequência respiratória, pulso).

- Solicitar o cartão da criança ou caderneta da criança para verificar a classificação nutricional e situação vacinal.

- Realizar a classificação e condutas segundo o roteiro da "Atenção Integral à Criança Doente - Estratégia de Atenção Integrada às Doenças Prevalentes da Infância (AIDPI)”.

- Informar o polo-base e sede DSEl sobre os casos graves e em observação, e encaminhar, se necessário.

O AIS não deve se recusar a ver os doentes, mas ao realizar a visita deve iniciar pelo acompanhamento das mulheres, das crianças e do Sisvan e depois buscar as queixas de doença.

Essa ordem de realização do trabalho poderá ser alterada se houver um caso de emergência no domicílio ou na comunidade.

EXemplo 3: Atividades comunitárias de preVenção e promoção da saúde da CRIAnÇA a SEREM DESENVOLVIDAS PELO AIS

- Discutir a situação de saúde das crianças, identificando os fatores de risco, situações de vulnerabilidade e problemas de saúde no ponto de vista da população e do AIS.

- Discutir a situação alimentar das crianças na comunidade, sem identificar pelo nome as crianças com baixo e muito baixo peso. Também deve discutir alternativas para melhoria da alimentação, principalmente o incentivo ao aleitamento materno e à oferta de alimentos ricos em ferro, vitamina $C$ e proteínas.

- Discutir a vacinação e sua importância, o calendário vacinal e a participação da comunidade nas ações de vacinação. Apresentar os resultados alcançados nas ações de vacinação.

- Orientar sobre a higienização oral das crianças e realizar atividades coletivas de escovação. 
- Caso ocorra epidemia de alguma doença (como gripe ou diarreia/desidratação), discutir com a comunidade as medidas a serem tomadas e informar o restante da equipe do polo-base sobre essas ocorrências.

EXEMPLO 4: ResponsabiLIDADES E ATRIBUIÇÕES DO RESTANTE DA EQUIPE

- Discutir com a comunidade e lideranças as ações a serem desenvolvidas por toda a equipe.

- Revisar o preenchimento da curva do crescimento no cartão da criança ou caderneta feito pelo AIS.

- Avaliar as crianças identificas pelo AIS com baixo peso e muito baixo peso e discutir as orientações e condutas com os AIS.

- Verificar e coletar os "Mapas Diários do Sisvan" preenchidos mensalmente pelo AIS.

- Discutir com as famílias e com o AIS a situação nutricional e alimentar das crianças da comunidade e as alternativas para a melhoria da alimentação.

- Discutir com o AIS e lideranças comunitárias sobre planejamento e execução das ações de vacinação.

- Realizar a vacinação das crianças.

- Discutir, presencialmente ou pela radiofonia, os casos de crianças doentes identificadas pelos AIS.

- Realizar atendimento das crianças identificadas pelo AIS como casos graves ou com necessidade de avaliação e realização de tratamento medicamentoso.

- Realizar atendimento odontológico.

- Participar, quando possível, das ações de prevenção e promoção de saúde desenvolvidas pelo AIS. 